\title{
Brønsted Acid lonic Liquids (BAILs) as Efficient and Recyclable Catalysts in the Conversion of Glycerol to Solketal at Room Temperature
}

Gui, Zhenyou; Zahrtmann, Nanette; Shunmugavel, Saravanamurugan; Reyero, Ines; Qi, Zhiwen; Bañares, Miguel A.; Riisager, Anders; Garcia-Suarez, Eduardo J.

Published in:

ChemistrySelect

Link to article, DOI:

$10.1002 /$ slct.201601600

Publication date:

2016

Document Version

Peer reviewed version

Link back to DTU Orbit

Citation (APA):

Gui, Z., Zahrtmann, N., Shunmugavel, S., Reyero, I., Qi, Z., Bañares, M. A., Riisager, A., \& Garcia-Suarez, E. J. (2016). Brønsted Acid lonic Liquids (BAlLs) as Efficient and Recyclable Catalysts in the Conversion of Glycerol to Solketal at Room Temperature. ChemistrySelect, 1(18), 5869-5873. https://doi.org/10.1002/slct.201601600

\section{General rights}

Copyright and moral rights for the publications made accessible in the public portal are retained by the authors and/or other copyright owners and it is a condition of accessing publications that users recognise and abide by the legal requirements associated with these rights.

- Users may download and print one copy of any publication from the public portal for the purpose of private study or research.

- You may not further distribute the material or use it for any profit-making activity or commercial gain

- You may freely distribute the URL identifying the publication in the public portal 
1

2

31

4

52

6

7

\title{
Brønsted Acid Ionic Liquids (BAILs) as Efficient and Recyclable Catalysts in the Conversion of Glycerol to Solketal at Room Temperature
}

Zhenyou Guia, , Nanette Zahrtmann", Dr. Saravanamurugan Shunmugavel ${ }^{\mathrm{a}}$, Ines Reyero ${ }^{\mathrm{c}}$, Dr. Zhiwen Qi $^{\mathrm{b}}$, Prof. Miguel A. Bañares $^{\mathrm{c}}$, Prof. Anders Riisager ${ }^{\mathrm{a},}$, Dr. Eduardo J. Garcia-Suarez ${ }^{\mathrm{a},{ }^{*}}$

${ }^{*}$ Corresponding authors

${ }^{a}$ Centre for Catalysis and Sustainable Chemistry, Department of Chemistry, Technical University of Denmark, DK-2800 Kgs. Lyngby, Denmark

${ }^{\mathrm{b}}$ State Key Laboratory of Chemical Engineering, School of Chemical Engineering, East China University of Science and Technology, Shanghai20023, China

${ }^{c}$ Catalytic Spectroscopy Laboratory, Instituto de Catálisis y Petroleoquímica, CSIC (ICP-CSIC), Marie Curie, 2, E-28049 Madrid, Spain

E-mail: $\underline{\text { edgar@kemi.dtu.dk; }} \underline{\text { ar@kemi.dtu.dk }}$

Fax: (+45) 45883136

\begin{abstract}
Brønsted acid ionic liquids (BAILs) have been prepared and applied for the first time - to the best of our knowledge - as efficient catalysts in the acetylation of glycerol with acetone to form solketal ((2,2dimethyl-1,3-dioxolan-4-yl)methanol) at very mild reaction conditions (room temperature) and short reaction times. The BAILs showed a superior catalytic performance in terms of both conversion and selectivity compared to the common mineral acid methanesulfonic acid as well as to other reported homogeneous and heterogeneous catalysts. Catalyst reusability was demonstrated with one of the BAILs (BAIL-1), which was recovered and reused by a simple procedure in four consecutive reaction runs without any loss of catalytic activity and selectivity. Thus, the BAILs combine the advantages of both homogeneous and heterogeneous catalysis with respect to excellent conversion and selectivity as well as easy recyclability.
\end{abstract}




\section{Introduction}

In the past century, the World has been largely dependent on oil as the main source for chemicals and energy production. In the coming years, the oil demand is expected to considerably increase due to the exponential economic growth of the emerging countries BRIC (Brazil, Russia, India and China). This increased demand in finite fossil resources, requires the development of new and sustainable sources for fuels and bulk chemicals. In this connection, biomass is a very attractive alternative feedstock, as it is the only widely available renewable carbon source. ${ }^{1}$

Biodiesel (fatty acid methyl ester; FAME) is already an applied renewable fuel produced in large-scale by transesterification of triglycerides from plant or animal oil with methanol in the presence of acid or basic catalysts. ${ }^{2}$ Due to its physicochemical properties, biodiesel is practically compatible with commercial diesel engines and provides similar fuel features as the fossil diesel. Moreover, the renewable nature offer added benefits such as, e.g. less toxicity, less emissions and biodegradation. ${ }^{3}$ Also notably, the synthesis of biodiesel yields glycerol in amounts corresponding to $10 \mathrm{wt}$ \% of the produced biodiesel as a potentially valuable resource. ${ }^{4}$ Glycerol has many applications areas in, for example, cosmetics, foods, pharmaceuticals and polymers, ${ }^{5}$ but the global biodiesel production generates amounts of glycerol that - if used - would saturate the current market and decrease its commercial value. Thus, a different strategy is to utilize glycerol as an attractive feedstock for production of value-added chemicals. ${ }^{7,8}$

Acetylation of glycerol with acetone to yield 2,2-dimethyl-1,3-dioxolane-4-methanol (i.e. solketal) has attracted special interest as an approach to utilize biodiesel glycerol, because solketal has direct applications as fuel additive, surfactant and flavoring agent. ${ }^{9-11}$ Solketal synthesis is generally carried out via condensation of glycerol and acetone in the presence of a Brønsted or Lewis acid catalyst (Scheme 1), which may be either dissolved (homogeneous) or solid (heterogeneous). ${ }^{4,12-15}$ The homogeneous catalysts, often strong mineral acids, such as methylsulfonic acid (MSA) are hampered by their recyclability, and the heterogeneous catalyst systems typically require cumbersome and expensive synthetic procedures.

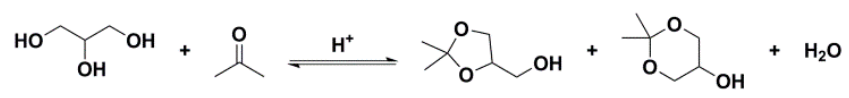

Scheme 1. Acetylation of glycerol with acetone in acid media 
Ionic liquids (ILs) are low-temperature molten salts (often liquid at room temperature) with intriguing physicochemical properties that can facilitate novel applications in diverse fields like, e.g. electrochemistry, analytics, tribology and catalysis. The nature of many IL ions allow them to be designed to accommodate functional groups, which can provide the ILs with auxiliary reactivity. ${ }^{16}$ In line with this, Davis and coworkers designed and synthesized Brønsted acid ILs (BAILs) in 2002. ${ }^{17}$ This class of task-specific ILs have since been applied in numerous traditionally mineral acid-catalyzed reactions as alternative catalyst and reaction media with good to excellent results. ${ }^{18-26}$ In this work, we report for the first time, the use of BAILs as efficient and reusable catalysts in the acetylation of glycerol with acetone to selectively yield solketal at room temperature and short reaction times.

\section{Results and discussions}

\subsection{Influence of reaction temperature and reaction time}

The acetylation of glycerol with acetone is an equilibrium reaction and the rate of the reaction is accordingly expected to depend on the reaction temperature, the acetone to glycerol ratio as well as the nature of the catalyst. The reaction was initially examined at acetone:glycerol molar ratio of 3:1 at different reaction temperatures from room temperature to $50{ }^{\circ} \mathrm{C}$ choosing BAIL-1 (figure 1) as catalyst. As shown in Figure 2, conversion and selectivity near 70 and $98 \%$, respectively, were achieved after $30 \mathrm{~min}$ at all examined reaction temperatures. The obtained conversion is expected to be reached faster at higher temperatures, but room temperature (approx. $24{ }^{\circ} \mathrm{C}$ ) was chosen as the preferred reaction temperature for further experiments.
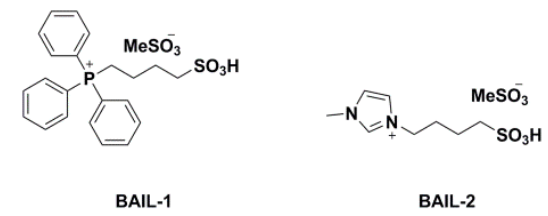

Figure 1. BAILs synthesized and applied in the acetylation of glycerol with acetone 
Figure 2. Influence of the reaction temperature in the acetylation of glycerol with acetone. Reaction conditions: 30 mmol glycerol (acetone:glycerol = 3:1), $0.2 \mathrm{~mol} \%$ BAIL-1 (based on glycerol), $30 \mathrm{~min}$.

Real-time Raman monitoring during reaction was done for all three catalysts (MSA, BAIL-1 and BAIL-2 (figure 1)), and the recorded Raman spectra are shown in Figure 3. The Raman bands of glycerol were rather weak in this spectral window, being located near $680 \mathrm{~cm}^{-1}$. The most informative bands were those at 638 and $648 \mathrm{~cm}^{-1}$, corresponding both to solketal, and that near $730 \mathrm{~cm}^{-1}$ associated to the formation of a glycerol and acetone adduct formed before cyclization into solketal, as pointed out recently by Stawicka and co-workers. ${ }^{27}$ The formation of the intermediate was apparent from the first few minutes and its evolution depended strongly on the catalytic system. Hence, for MSA the adduct formation went through a maximum after 2-3 min of reaction, where after it remained present during the rest of the experiment affecting the reaction selectivity. In contrast, the conversion of the intermediate adduct was faster in the presence of the BAILs, thus resulting in higher reaction selectivity for the BAILs compared to MSA under the studied reaction conditions. 

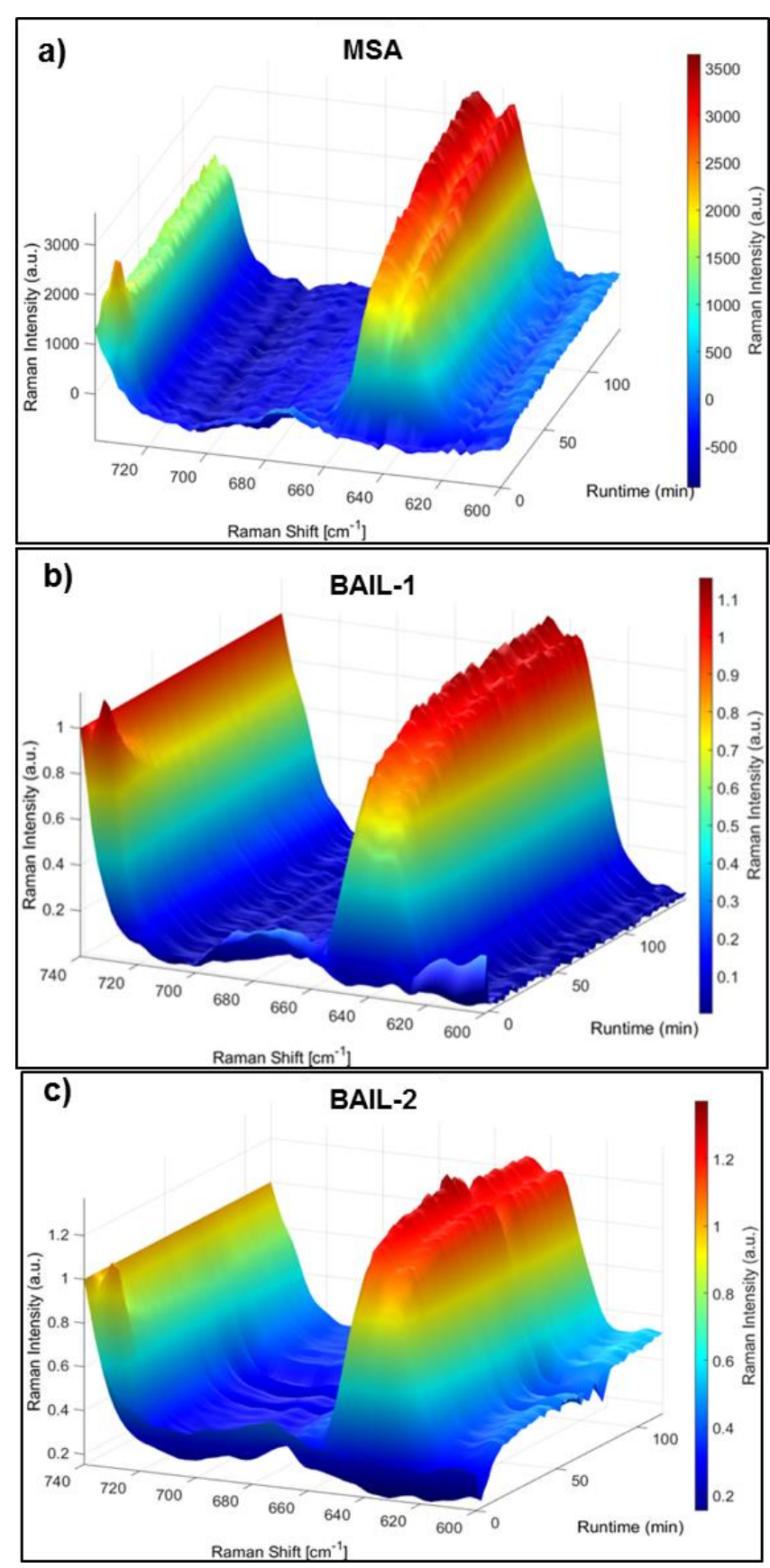

Figure 3. Real-time Raman monitoring in the acetylation of glycerol with acetone with catalyst a) MSA, b) BAIL-1 and c) BAIL-2. Reaction conditions: $30 \mathrm{mmol}$ glycerol (acetone:glycerol = 3:1), $0.2 \mathrm{~mol} \%$ catalyst (based on glycerol), room temperature.

A time study of the reaction at room temperature with BAIL-1 revealed that the glycerol conversion increased linearly up to 30 min runtime, but remained unchanged at longer reaction times confirming that equilibrium was reached already at 30 min reaction (Figure 4a). Noteworthy, the selectivity also changed slightly with reaction time only reaching the $98 \%$ after 30 min suggesting that an intermediate 
was formed during the reaction, as also monitored with real-time Raman (Figure 3) and further

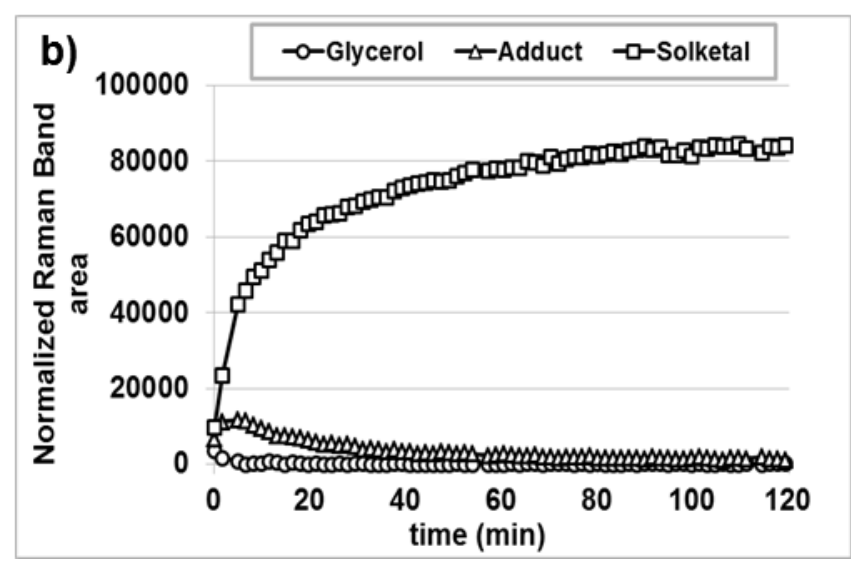

Figure 4. Influence of the reaction time in the acetylation of glycerol with acetone represented by a) GC analysis and b) normalized area of bands during real-time Raman monitoring. Reaction conditions: 30 mmol glycerol (acetone:glycerol = 3:1), 0.2 mol\% BAIL-1 (based on glycerol), room temperature.

\subsection{Influence of the catalyst type and catalyst loading}

The acetylation performance of the two prepared BAILs were compared with MSA in more detail at room temperature with acetone:glycerol molar ratio 9:1 (Figure 5). The two tested BAILs yielded similar high selectivity to the solketal ( 98 \%), while BAIL-1 containing a phosphonium cation gave slightly higher conversion after 15 min reaction than BAIL-2 with an imidazolium cation (88 vs $84 \%$ ). Notably, both BAILs performed better than MSA at the same reaction conditions when using both 0.2 and $1.4 \mathrm{~mol} \%$ MSA (based on glycerol), as only 63 and $74 \%$ conversion and selectivity of 90 and 98 $\%$, respectively, were obtained here. The shorter reaction time of $15 \mathrm{~min}$ allowed the activity differences of the catalysts to be measured prior to equilibrium was reached.

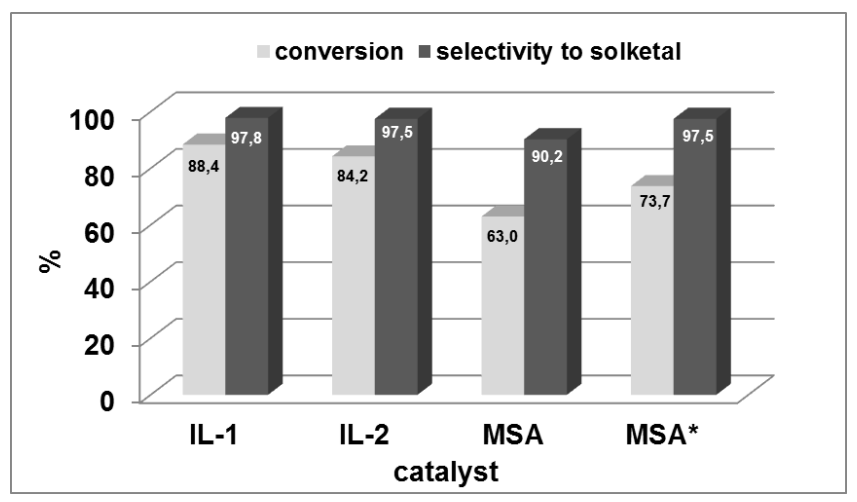


Figure 5. Influence of the reaction temperature in the acetylation of glycerol with acetone. Reaction conditions: $30 \mathrm{mmol}$ glycerol (acetone:glycerol = 9:1), $0.2 \mathrm{~mol} \%$ catalyst (based on glycerol), room temperature, $15 \mathrm{~min}$. *1.4 mol\% MSA (based on glycerol).

7

The effect of the catalyst concentration on the reaction was studied by testing different amount of BAIL-1 corresponding to $0.1-0.8 \mathrm{~mol} \%$ (based on glycerol) with a reaction of $15 \mathrm{~min}$ and an acetone:glycerol ratio of 3:1. As shown in Figure 6, the maximum conversion rate was achieved with $0.4 \mathrm{~mol} \%$ catalyst $\left(\mathrm{TOF}=661 \mathrm{~h}^{-1}\right.$; mol glycerol converted per mol catalyst per hour), while further increase of catalyst loading didn’t affect neither conversion nor selectivity.

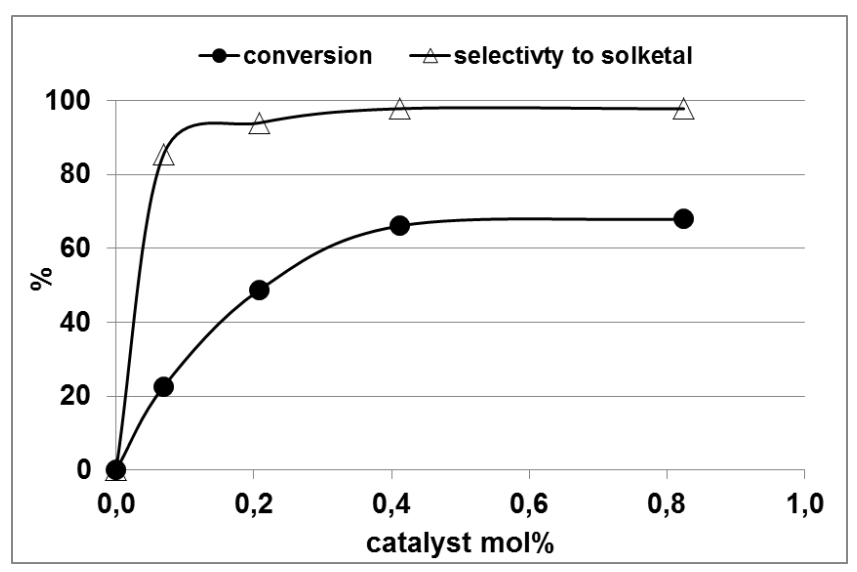

Figure 6. Influence of the catalyst loading (mol\% based on glycerol) in the acetylation of glycerol with acetone. Reaction conditions: $30 \mathrm{mmol}$ glycerol (acetone:glycerol = 3:1), room temperature, $15 \mathrm{~min}$.

\subsection{Influence of the acetone to glycerol ratio}

As mentioned above, the acetylation of glycerol with acetone is an equilibrium reaction and the solketal product formation is therefore dependent on the concentrations of the reactants. Hence, when the initial acetone to glycerol ratio is increased the glycerol conversion is also anticipated to increase. Reactions with different ratios were tested using BAIL-1 as catalyst at room temperature and 30 min reaction time (Figure 7). As expected, the highest conversion was indeed achieved with acetone:glycerol ratio of 15 (100\% conversion, $98 \%$ selectivity), while lower conversions were obtained at lower ratios. 
Figure 7. Influence of the acetone:glycerol ratio in the acetylation of glycerol with acetone. Reaction conditions: $30 \mathrm{mmol}$ glycerol, $0.2 \mathrm{~mol} \%$ BAIL-1 (based on glycerol), room temperature, $30 \mathrm{~min}$.

\subsection{Recycling experiments}

Catalyst recovery and recycling with maintenance of catalytic performance are generally challenging for homogeneous catalyst systems. Here, the recycling potential of the prepared BAIL-1 catalyst was evaluated for the acetylation reaction at room temperature after 15 min reaction time with $400 \mathrm{mg}$ of catalyst near to full glycerol conversion (Figure 8). The catalyst showed to be easy to recycle after precipitation with diethyl ether and centrifugation/filtration, and maintained catalytic performance with respect to both conversion (92-96\%) and selectivity ( 98\%) in at least four consecutive reaction runs. The ease of preparation of BAIL-1 - two reaction steps and no special handling - as well as its excellent catalytic performance makes this catalyst superior to most of the homogeneous and heterogeneous Brønsted acid catalysts reported so far for acetylation reactions like the solketal formation.

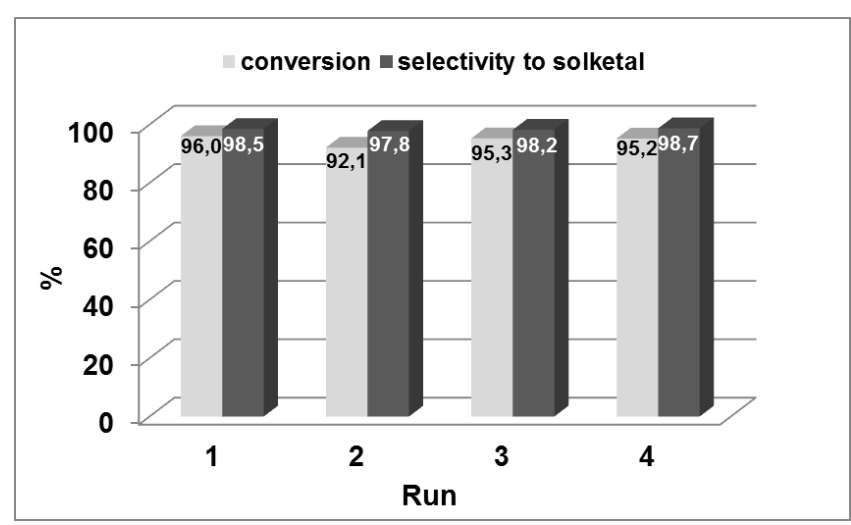

Figure 8. Recycling experiments with BAIL-1 in the acetylation of glycerol with acetone. Reaction conditions: 30 mmol glycerol (acetone: glycerol = 15:1), $400 \mathrm{mg}$ BAIL-1 (2.7 mol\% based on glycerol), room temperature, $15 \mathrm{~min}$.

\section{Conclusions}


Brønsted acid ILs (BAILs) have been prepared and applied for the first time - as far as we are aware as catalysts in the acetylation of glycerol with acetone to form solketal at very mild reaction conditions. Quantitative glycerol conversion and $98 \%$ selectivity towards solketal were achieved with only 0.2 mol\% BAIL-1 catalyst after $30 \mathrm{~min}$ reaction at room temperature, which is superior performance compared to the common mineral acid MSA as well as other homogeneous and heterogeneous catalysts reported in the literature for this reaction. Real-time Raman monitoring confirmed the formation of an intermediate adduct during the first minutes of the reaction using both BAILs and MSA, but adduct conversion was more facile with the former catalysts thereby resulting in higher selectivity. Importantly, the BAIL-1 catalyst could further be recycled up to four times without any loss of catalytic activity and selectivity.

In summary, the reported BAILs are prepared in a simple, two step synthesis procedure and combine the advantages of both homogeneous and heterogeneous catalysis with respect to excellent conversion and selectivity as well as easy separation and reuse.

\section{Supporting Information}

All experimental details about Brønsted Acid Ionic Liquids synthesis and characterization (NMR, TGA, Raman Spectroscopy and Hammett acidity functions) as well as the acetylation and recycling procedures are reported in the attached Supporting Information

\section{Acknowledgements}

The Spanish Ministry (CTQ2014-57578-R project), the Chinese State Scholarship Fund (No. 201506740037), the National Natural Science Foundation of China (NSFC 21476084 and 21576081), the Fundamental Research Funds for the Central Universities, PetroChina Innovation Foundation and the Open Project of Shanghai Key Laboratory of Molecular Catalysis and Innovative Materials (2014MCIMKF02) are acknowledged for supporting the work.

\section{Keywords}

Acetylation; Brønsted Acid Ionic Liquids; Catalyst recovery; Raman Spectroscopy; Solketal.

\section{References}


[1] G.W. Himmel, S.Y. Ding, D.K. Johnson, W.S. Adney, M.R. Nimlos, J.W. Brady, T. Foust, Science, 2007, 315, 804-807.

182

[2] B. Freedman, E. H. Pryde, T. L. Mounts, J. Am. Oil Chem. Soc., 1984, 61, 1638-1643.

183 10

[3] G. Vicente, M. Martinez, J. Aracil, Bioresour. Technol., 2004, 92, 297-305.

[4] J. I. Garcia, H. Garcia-Marin, E. Pires, Green Chem., 2010, 12, 426-434.

[5] S. Claude, Lipid Fett, 1999, 101, 101-104.

[7] M. Pagliaro, R. Ciriminna, H. Kimura, M. Rossi, C. Della Pina, Angew. Chem., Int. Ed., 2007, 46, 44344440.

[8] C. Zhou, J. N. Beltramini, Y. Fana, G. Q. Lu, Chem. Soc. Rev., 2008, 37, 527-549.

[9] H. Noureddini, U.S. Patent 6015 440, 2000.

[10] H. Noureddini, U.S. Patent 6174 501, 2001.

[11] A. Behr, L. Obendorf, Eng. Life Sci., 2002, 2, 185-189.

[12] G. Vicente, J. A. Melero, G. Morales, M. Paniagua, E. Martin, Green Chem., 2010, 12, 899-907.

[13] M. S. Newman, M. Renoll, J. Am. Chem. Soc., 1945, 67, 1621-1621.

[14] P. Manjunathan, S. P. Maradur, A. B. Halgeri, G. V. Shanbhag, Journal of Molecular Catalysis A: Chemical, 2015, 396, 47-54.

[15] B. Mallesham, P. Sudarsanam, G. Raju, B. M. Reddy, Green Chem., 2013, 15, 0478-489.

[16] Ionic Liquids in Synthesis, ed. P. Wasserscheid and T. Welton, Wiley, 2007

[17] A. C. Cole, J. L. Jensen, I. Ntai, K. L. T. Tran, K. J. Weaver, D. C. Forbes and J. H. Davis, J. Am. Chem. Soc., 2002, 124, 5962-5963.

[18] F. Dong, C. Jian, F. Zhenghao, G. Kai and L. Zuliang, Catal. Commun., 2008, 9, 1924-1927.

[19] X. Lia, W. Eli and G. Lia, Catal. Commun., 2008, 9, 2264-2268.

[20] P. Wasserscheid, M. Sesing, W. Korth, Green Chem., 2002, 4, 134-138.

[21] D. Li, F. Shi, S. Guo, Y. Deng, Tetrahedron Lett., 2004, 45, 265-268.

[22] Y. L. Gu, J. Mol. Catal. A: Chem., 2004, 212, 71-75.

[23] S. Saravanamurugan, A. Riisager, Catal. Today, 2013, 200, 94-98.

[24] J. C. Serrrano-Ruiz, J. M. Campelo, M. Francavilla, A. A. Romero, R. Luque, C. Menendez-Vazquez, A. B. Garcia, E. J. Garcia-Suarez, Catal. Sci. Tech., 2012, 9, 1828-1832.

[25] H. Zhang, F. Xu, G. Zhang and C. Wang, Green Chem., 2007, 9, 1208-1211. 
2309 [26] E. J. Garcia-Suarez, S. G. Khokarale , O. N. van Buu , R. Fehrmann, A. Riisager, Green Chem., 2014, 16, 210 161-166.

211 [27] K. Stawicka, A. E. Diaz-Alvarez, V. Calvino-Casilda, M. Trejda, M. A. Bañares, M. Ziolek, J. Phys. Chem. 2012 C, 2016, 120,16699-16711. 
Click here to access/download Supporting Information SupportingInformation(ChemistrySelect).pdf 


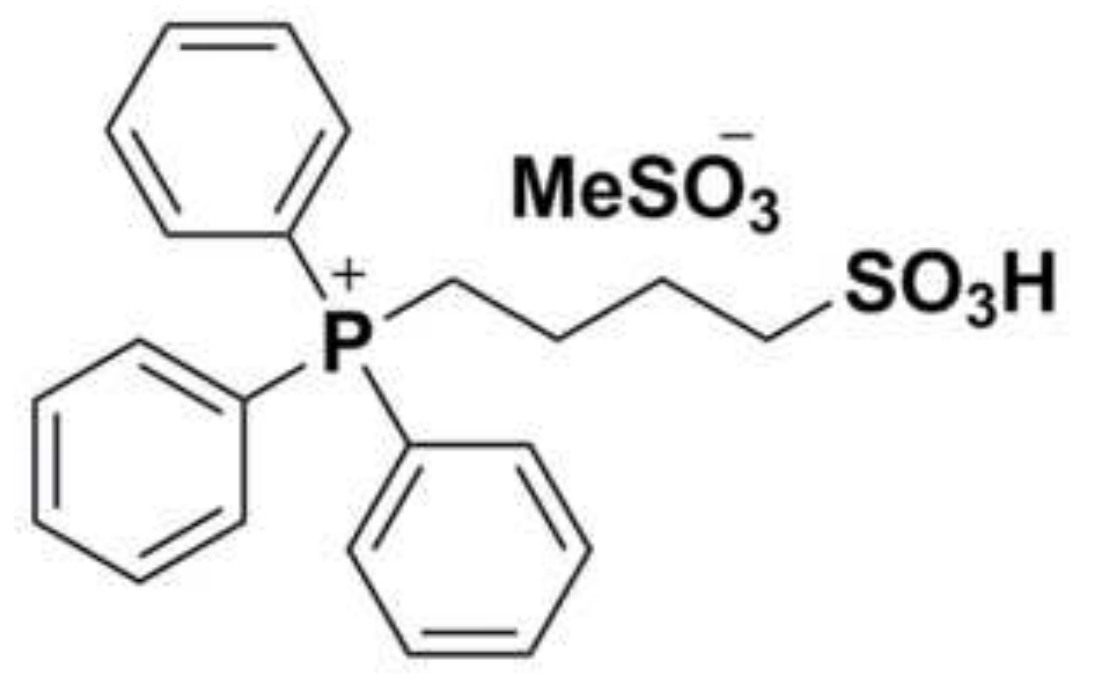

BAIL-1

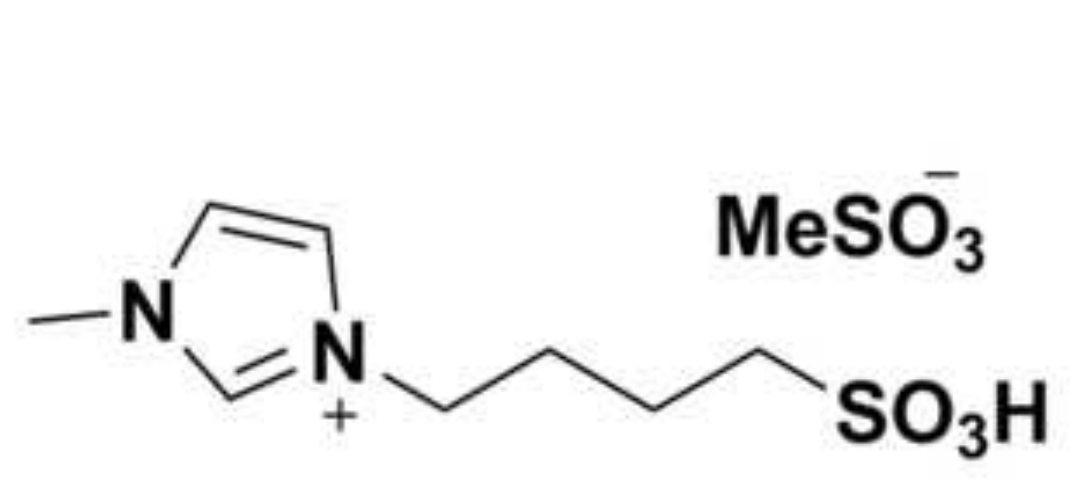

BAIL-2 


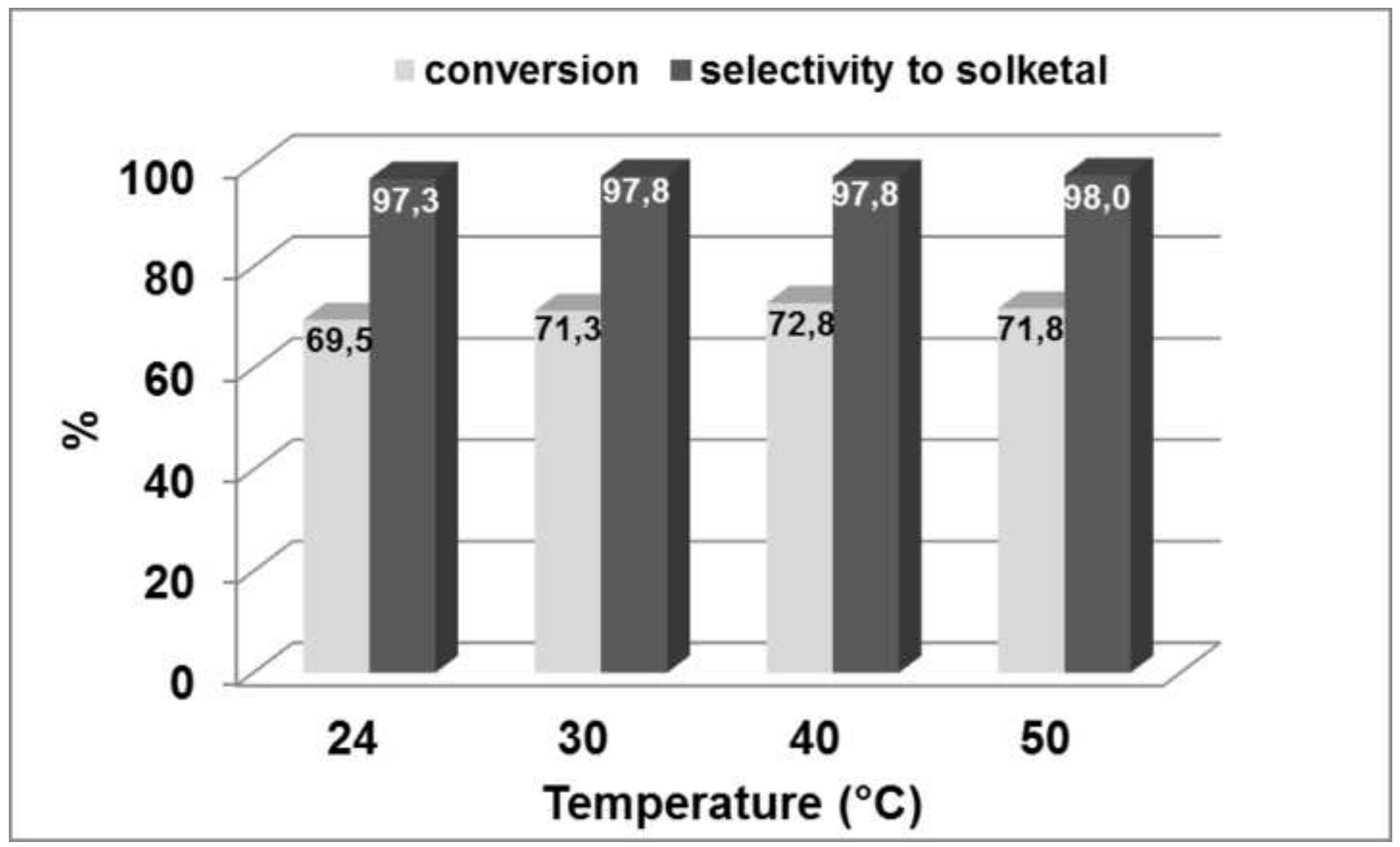

conversion selectivity to solketal 

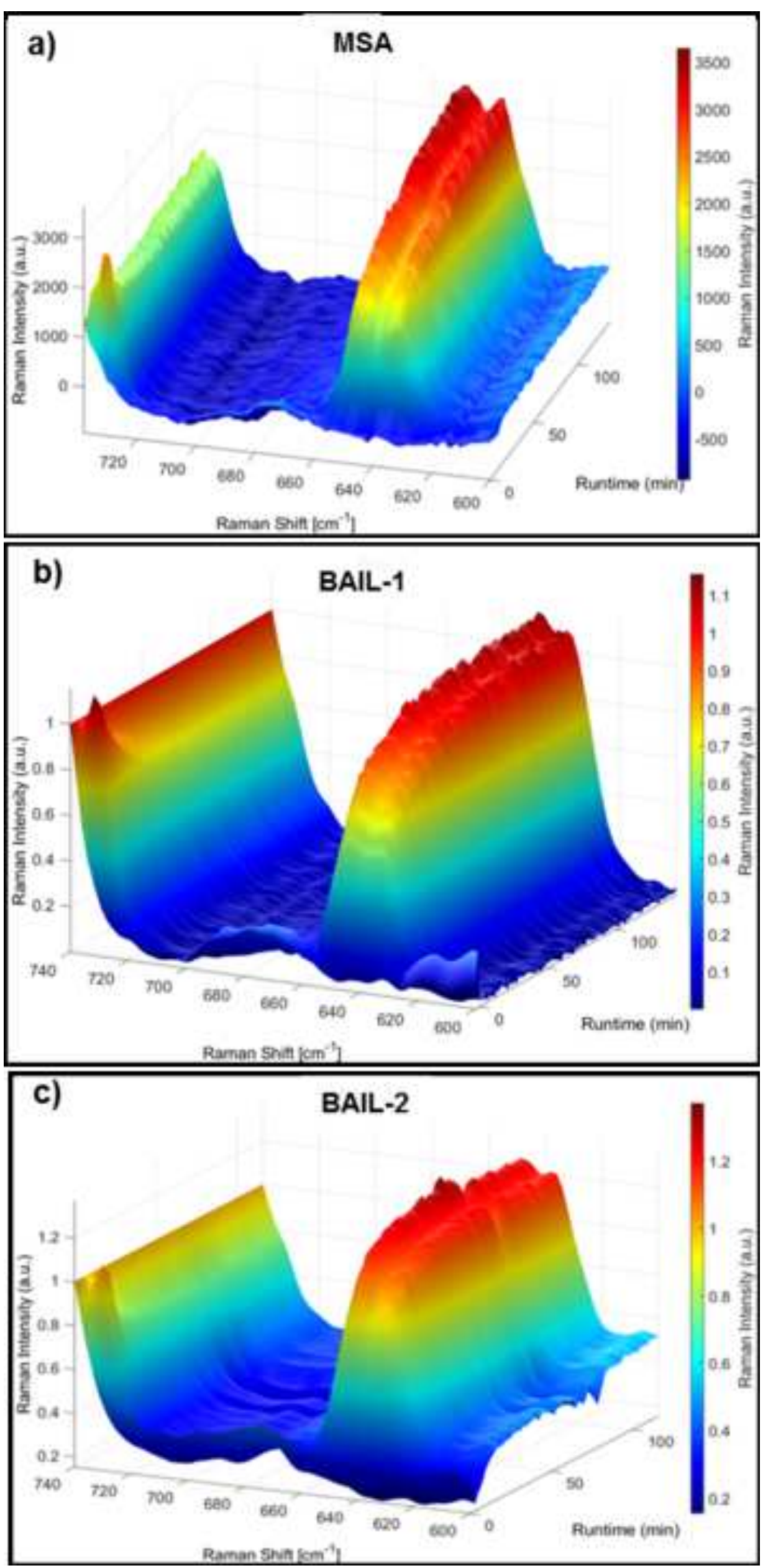


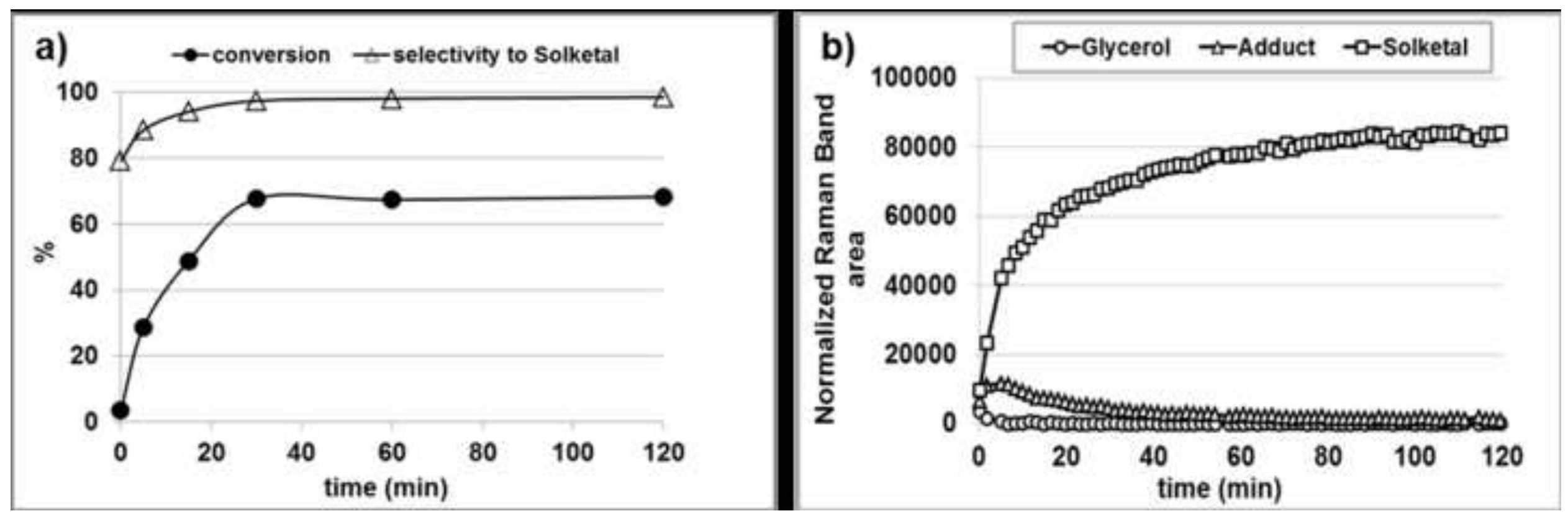




\section{conversion selectivity to solketal}

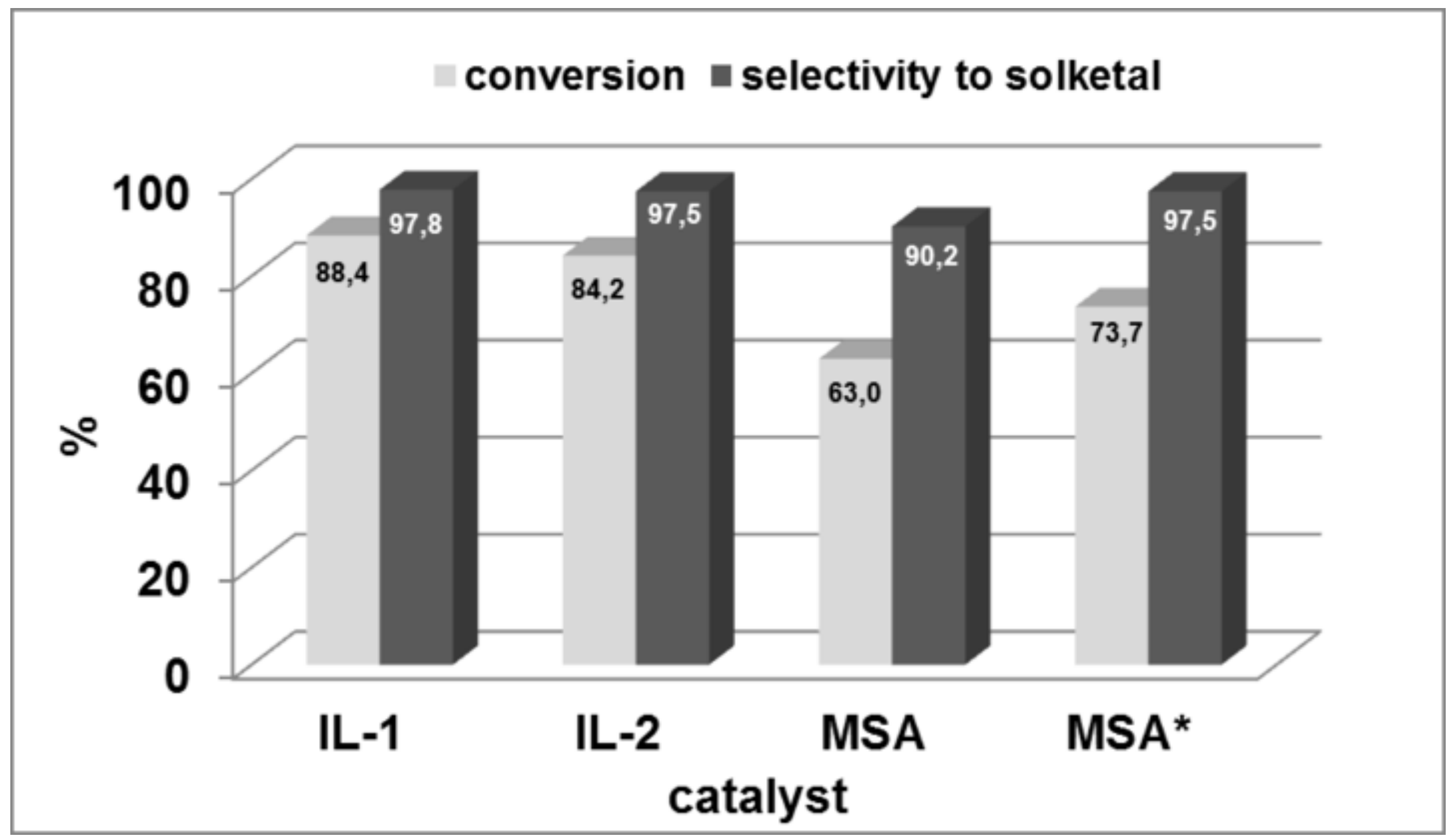




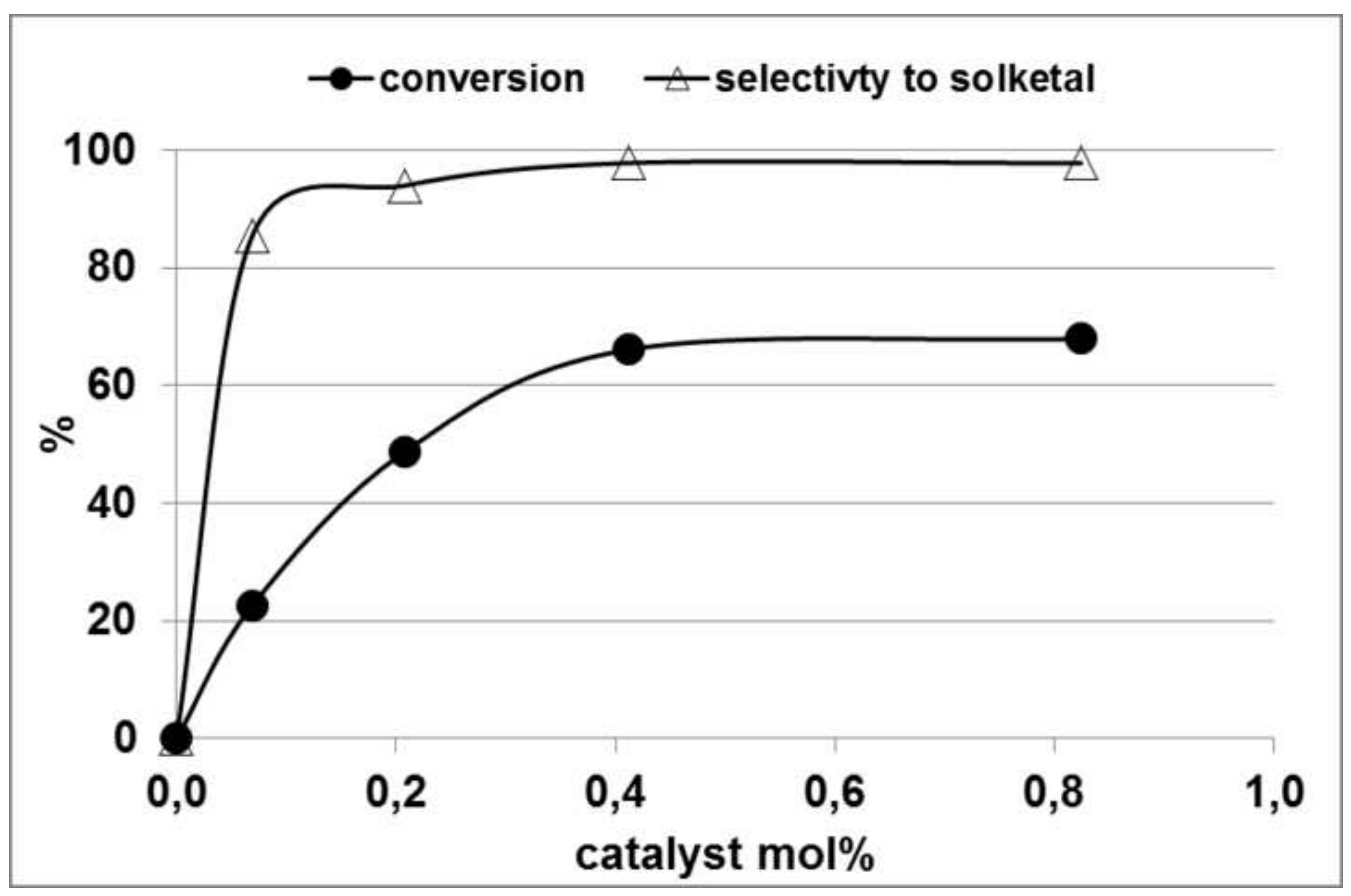




\section{conversion selectivity to solketal}

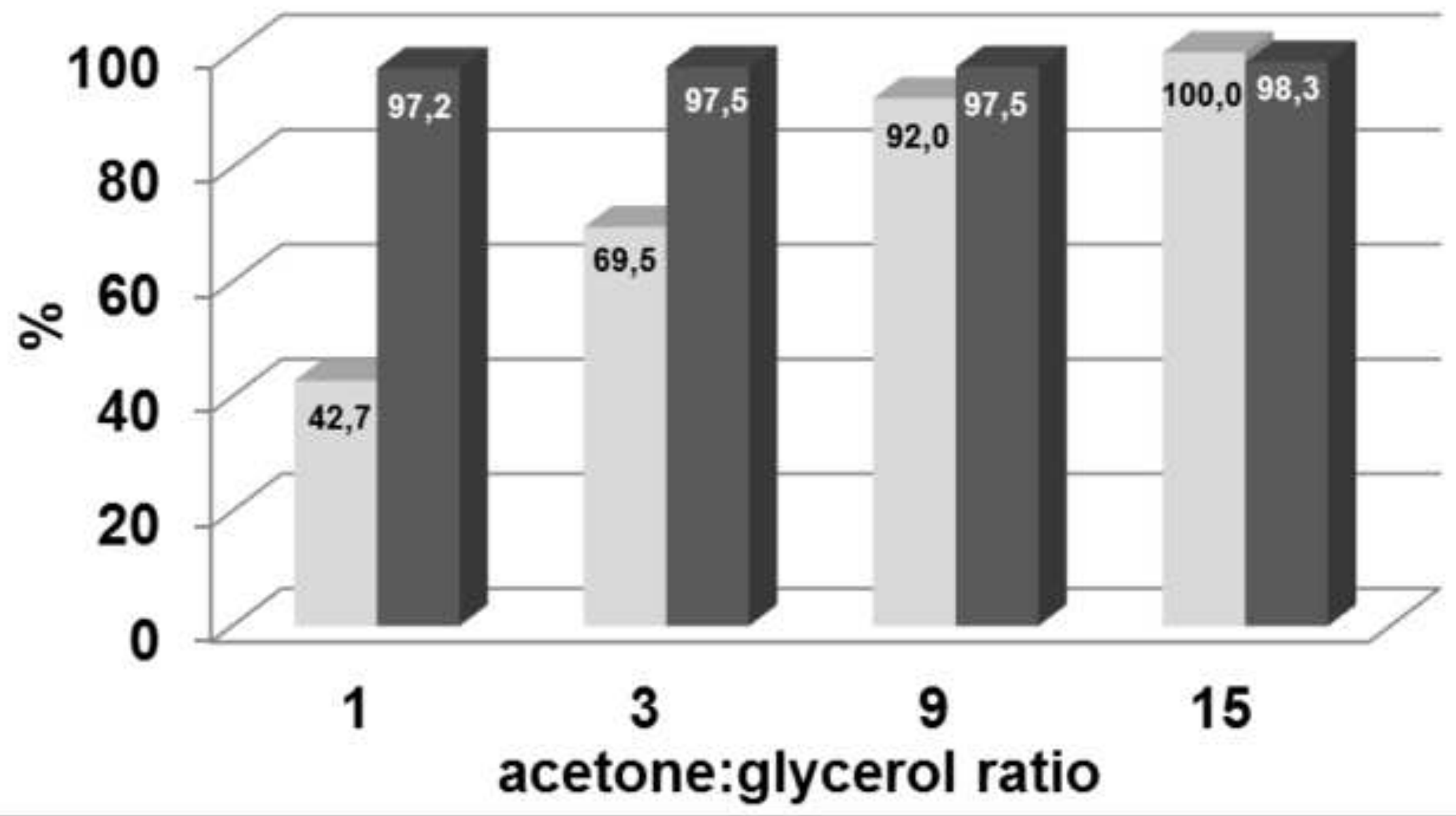




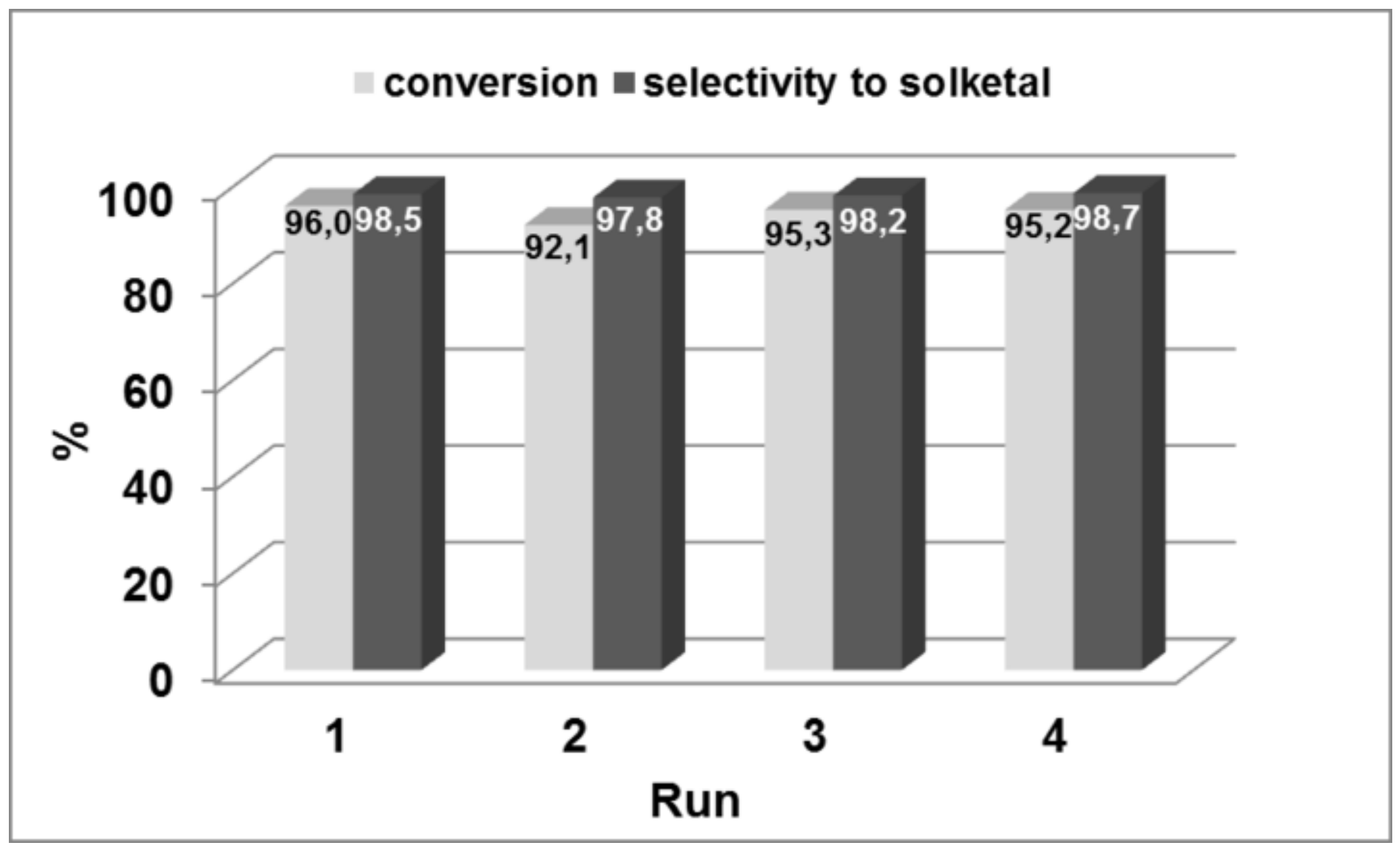

\section{conversion a selectivity to solketal}




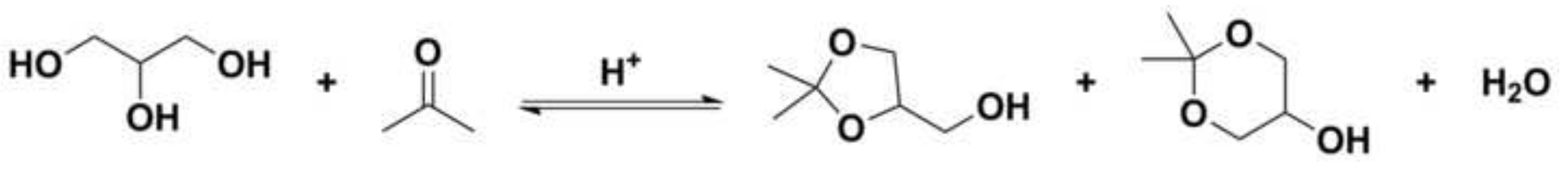




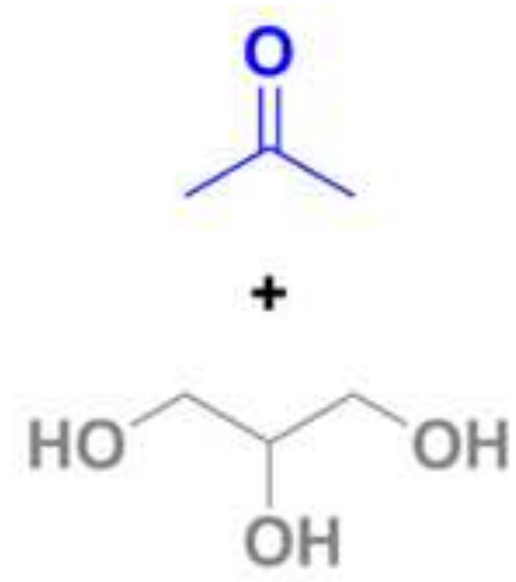

\section{Brønsted Acid Ionic Liquids (BAILs)}

mild reaction conditions (RT)
$+\mathrm{H}_{2} \mathrm{O}$ 


\section{Click here to access/download \\ Additional Material - Author
TOCtext.docx Additional Material - Author
TOCtext.docx

Author
r

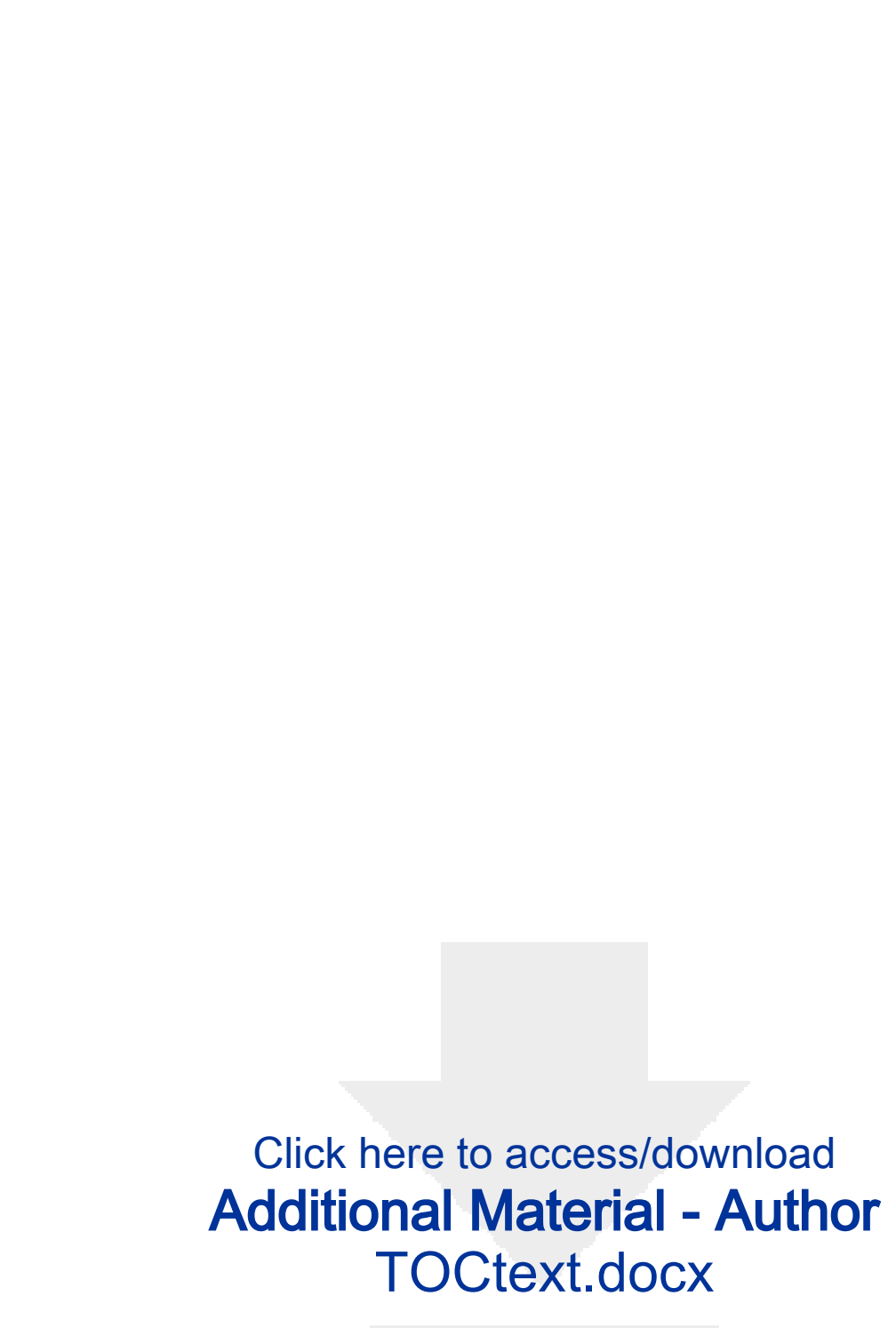

